\title{
Explaining the increased health care expenditures associated with gastroesophageal reflux disease among elderly Medicare beneficiaries with chronic obstructive pulmonary disease: a cost-decomposition analysis
}

This article was published in the following Dove Press journal:

International Journal of COPD

8 April 2014

Number of times this article has been viewed

Mayank Ajmera'

Amit D Raval'

Chan Shen ${ }^{2}$

Usha Sambamoorthi'

'Department of Pharmaceutical Systems and Policy, School of Pharmacy, School of Medicine, West Virginia University, Morgantown, WV, USA; ${ }^{2}$ Department of Biostatistics and Health Services Research, University of Texas MD Anderson Cancer Center, Houston, TX, USA

Correspondence: Mayank Ajmera I Medical Center Drive, Robert C Byrd Health Sciences Center-North, Department of Pharmaceutical Systems and Policy, School of Pharmacy, West Virginia University, Morgantown, WV 26506, USA Tel + I 304293 I442

Email mrajmera@hsc.wvu.edu
Objective: To estimate excess health care expenditures associated with gastroesophageal reflux disease (GERD) among elderly individuals with chronic obstructive pulmonary disease (COPD) and examine the contribution of predisposing characteristics, enabling resources, need variables, personal health care practices, and external environment factors to the excess expenditures, using the Blinder-Oaxaca linear decomposition technique.

Methods: This study utilized a cross-sectional, retrospective study design, using data from multiple years (2006-2009) of the Medicare Current Beneficiary Survey linked with feefor-service Medicare claims. Presence of COPD and GERD was identified using diagnoses codes. Health care expenditures consisted of inpatient, outpatient, prescription drugs, dental, medical provider, and other services. For the analysis, $t$-tests were used to examine unadjusted subgroup differences in average health care expenditures by the presence of GERD. Ordinary least squares regressions on log-transformed health care expenditures were conducted to estimate the excess health care expenditures associated with GERD. The Blinder-Oaxaca linear decomposition technique was used to determine the contribution of predisposing characteristics, enabling resources, need variables, personal health care practices, and external environment factors, to excess health care expenditures associated with GERD.

Results: Among elderly Medicare beneficiaries with COPD, 29.3\% had co-occurring GERD. Elderly Medicare beneficiaries with COPD/GERD had 1.5 times higher $(\$ 36,793$ vs $\$ 24,722$ $[P<0.001])$ expenditures than did those with COPD/no GERD. Ordinary least squares regression revealed that individuals with COPD/GERD had 36.3\% $(P<0.001)$ higher expenditures than did those with COPD/no GERD. Overall, $30.9 \%$ to $43.6 \%$ of the differences in average health care expenditures were explained by differences in predisposing characteristics, enabling resources, need variables, personal health care practices, and external environment factors between the two groups. Need factors explained up to $41 \%$ of the differences in average health care expenditures between the two groups.

Conclusion: Among elderly Medicare beneficiaries with COPD, the presence of GERD was associated with higher expenditures. Need factors primarily contributed to the differences in average health care expenditures, suggesting that the comanagement of chronic conditions may reduce excess health care expenditures associated with GERD.

Keywords: Blinder-Oaxaca linear decomposition, geriatrics, comorbidities, respiratory disease, esophageal disease 


\section{Introduction}

Chronic obstructive pulmonary disease (COPD), characterized by progressive and persistent airflow limitation, ${ }^{1-3}$ is associated with high economic burden, ${ }^{4}$ with $\$ 29.5$ billion spent on direct costs annually. ${ }^{2}$ Prior research has documented that COPD exacerbations can be the key drivers of health care expenditures ${ }^{5,6}$ accounting for approximately $70 \%$ of all direct costs. ${ }^{7,8}$ Often, co-occurring chronic conditions among individuals with COPD may be associated with frequent COPD exacerbations. ${ }^{9}$

Specifically, gastroesophageal reflux disease (GERD), a highly prevalent co-occurring condition among individuals with COPD, ${ }^{10}$ can lead to frequent COPD exacerbations. ${ }^{11-15}$ A systematic review, with meta-analysis of randomized controlled trials and observational studies, found that the presence of GERD is an independent and significant predictor of COPD exacerbations ${ }^{15}$ and that individuals with COPD and GERD had seven times the risk of experiencing COPD exacerbations as compared with those with COPD but no GERD (relative risk $[\mathrm{RR}]=7.57 ; 95 \%$ confidence interval $[\mathrm{CI}]: 3.84-14.94) .{ }^{15}$

Therefore, the presence of GERD can lead to higher health care utilization and expenditures compared with those with COPD and no GERD. Researchers, using the National Health Insurance Database of Korea, have reported that among nonelderly and elderly individuals, those with COPD and GERD had an increased likelihood of hospitalizations (adjusted odds ratio [OR] 1.54, 95\% CI: $1.50-1.58$ ) and emergency room (ER) visits (OR 1.55, 95\% CI: 1.48-1.62) as compared with those with COPD but no GERD. ${ }^{16}$ However, to date, no study has estimated the excess health care expenditures associated with GERD among elderly individuals with COPD. It is important to conduct research among the elderly as COPD prevalence rates are twice as high among elderly individuals ( $>65$ years) as compared with young adults (45-64 years). ${ }^{17,18}$ In addition, multiple chronic conditions are the norm rather than the exception among the elderly individuals with COPD. ${ }^{19}$ Furthermore, it is important to understand the factors associated with excess health care expenditures among individuals with COPD and GERD so as to develop clinical and programmatic interventions to reduce health care expenditures.

Therefore, the primary objective of the study was to estimate the excess health care expenditures associated with GERD among elderly individuals with COPD and examine the extent to which predisposing characteristics, enabling resources, need variables, personal health care practices, and external environment explain the excess expenditures associated with GERD among elderly individuals with COPD.

\section{Methods}

\section{Study design}

This study adopted a cross-sectional study design with retrospective observational data to examine excess health care expenditures associated with GERD among elderly individuals with COPD.

\section{Data source}

The data for this study were derived from the nationally representative survey of Medicare beneficiaries, Medicare Current Beneficiary Survey (MCBS). The MCBS is a continuous, multipurpose survey of a nationally representative sample of aged, disabled, and noninstitutionalized Medicare beneficiaries..$^{20}$ The MCBS consists of two modules: 1) "access to care" and 2) "cost and use." For this study, we used the cost and use module that contains information regarding health care use, prescription drug use, and personal health care practices for all the Medicare beneficiaries. Additionally, the MCBS provides detailed information on expenditures and sources of payment for all services used by Medicare beneficiaries, including copayments, deductibles, and noninsured services.

To ensure adequate sample size, the current study pooled cross-sectional annual releases of the cost and use files for the years 2006-2009. As the years were pooled, the study sample represents person-years rather than persons. However, we use the term Medicare beneficiaries rather than person-year for ease of presentation.

\section{Analytical sample Identification of elderly with chronic obstructive pulmonary disease}

Elderly Medicare beneficiaries aged $>65$ years with COPD were identified using the International Classification of Diseases, Ninth Revision, Clinical Modification (ICD-9-CM) codes for chronic bronchitis (491.xx) or emphysema (492.xx) or unspecified chronic airway obstruction (496.xx). These diagnosis codes have been utilized in published research to identify individuals with COPD and to evaluate their health outcomes. ${ }^{21-23}$ Use of one or more hospitalizations and one or more outpatient encounters with COPD diagnosis has been found to have a sensitivity of $85.0 \%$ (95\% CI: 77.0-91.0) and specificity of $78.4 \%$ (95\% CI: $73.6-82.7) .{ }^{24}$ For the current study, individuals with at least one inpatient visit or two outpatient visits (14 days apart) with COPD codes were considered to have diagnosed COPD.

Additional inclusion criteria were: community-dwelling, fee-for-service Medicare beneficiaries with full-year 
enrollment during the calendar year. Based on all the selection criteria the final sample consisted of 2,461 elderly Medicare beneficiaries.

\section{Dependent variable: total health care expenditures}

Total health care expenditures (hereafter referred to as health care expenditures) were derived using sources of payment and types of services. Health care expenditures were calculated by adding the expenditures for inpatient, outpatient, prescription drugs, dental, medical provider, and other services. Sources of payment included third-party payers, such as Medicare, Medicaid, Veterans Affairs Health Insurance, private health maintenance organizations, employer-sponsored insurance providers, individually purchased insurance providers, and other payers.

To account for medical services inflation, expenditures in 2006, 2007, and 2008 were converted to 2009-equivalent dollars, using the annual consumer price index for medical care services available from the Bureau of Labor Statistics. ${ }^{25}$ As expenditures data were skewed to the right, we transformed expenditures to a natural logarithmic scale, and used log-transformed expenditures as the dependent variable in the regression analyses.

\section{Key independent variable: GERD (yes/no)}

A binary indicator variable for the presence or absence of GERD was used as the key independent variable. For the ease of presentation, individuals with GERD are referred as the "COPD/GERD" group and those without GERD are referred as the "COPD/no GERD" group. Elderly Medicare beneficiaries with GERD were identified using inpatient/ outpatient claims with ICD9 CM codes: 530.81 (esophageal reflux, which includes gastroesophageal reflux) and 530.1x (reflux esophagitis, which includes abscess of esophagus; esophagitis due to a nitric oxide synthase, chemical, peptic, postoperative, or regurgitant cause). These codes have been used in prior research for identifying GERD from administrative claims data. ${ }^{26}$

\section{Other independent variables}

To identify the factors that contributed to the excess health care expenditures associated with COPD/GERD, the Anderson health care behavior/utilization model was used. ${ }^{27}$ Based on this model, independent variables were grouped into: predisposing characteristics, enabling resources, need variables, personal health care practices, and external environment.
Predisposing characteristics included sex (women or men), age in years $(65-69,70-74, \geq 75)$, and race/ethnicity (White, African American, Latino, or “Other”). Enabling resources included marital status (married or nonmarried), education (less than high school, high school, more than high school), poverty status ( $<200 \%$ of the federal poverty line [FPL], $200 \%-400 \%$ of FPL, $>400 \%$ of FPL), and Medicaid coverage (yes or no). Need variables consisted of perceived physical health status (excellent, very good, good, fair, or poor), Charlson's comorbidity index (CCI) score, and presence of mental health conditions (anxiety or depression). Personal health care practices included body mass index categories (underweight [0-18.5 kg/m²], normal [18.5-25.0 $\left.\mathrm{kg} / \mathrm{m}^{2}\right]$, overweight $\left[25.0-30.0 \mathrm{~kg} / \mathrm{m}^{2}\right]$, or obese $[\geq 30.0 \mathrm{~kg} /$ $\left.\mathrm{m}^{2}\right]$ ), and smoking status (current, past, never). External environment was measured using metropolitan-dwelling status (urban vs rural).

\section{Statistical analysis}

Unadjusted subgroup differences by the presence or absence of GERD were tested using chi-square tests of independence. As well, $t$-tests were used to examine statistically significant differences in average health care expenditures among the GERD and no GERD groups. To understand the association between GERD status and log-transformed health care expenditures, multivariable ordinary least squares (OLS) regressions were used. In these regressions, health care expenditures was the dependent variable, and the independent variables were predisposing characteristics, enabling resources, need variables, personal health care practices, and external environment. For continuous variables, the parameter estimates obtained from the OLS regressions were exponentiated and interpreted as the percent change for each unit change in the independent variable. For the categorical variables, percent change in expenditure was calculated by the formula $\exp ^{(\beta)}-1 .{ }^{28} \mathrm{All}$ analyses were conducted using survey procedures within statistical analysis system software (SAS ${ }^{\circledR}$ version 9.3; SAS Institute Inc., Cary, NC, USA).

\section{Blinder-Oaxaca decomposition analyses}

The Blinder-Oaxaca decomposition analyses, a wellaccepted regression-based technique, was used to explain the extent to which predisposing characteristics, enabling resources, need variables, personal health care practices, and external environment contributed to differences in average health care expenditures by GERD status..$^{29,30}$ Using this approach, the difference in average health care expenditures between COPD/GERD and COPD/no GERD was divided 
into two parts: an explained and unexplained portion. The explained portion, also referred to as "characteristics effect," represented differences in average expenditures due to differences in observed characteristics between the two groups (GERD and no GERD). In other words, the explained portion assessed how much of the differences in average expenditures between "COPD/GERD" and "COPD/no GERD" could be attributed to differences in predisposing characteristics, enabling resources, need variables, personal health care practices, and external environment between the two groups.

The unexplained portion, also referred to as "coefficients effect," represented differences in average expenditures that could not be explained, either because of differences in unobserved or unmeasured characteristics between the two groups (COPD/GERD and COPD/no GERD) or differences in regression coefficient estimates between the two groups.

The explained portion was calculated by multiplying the difference in average characteristics between the COPD/ GERD and COPD/no GERD groups with regression weights. Alternative ways of estimating regression weights have been proposed by Blinder and Oaxaca, ${ }^{29,30}$ Cotton, ${ }^{31}$ Neumark, ${ }^{32}$ Oaxaca and Ransom, ${ }^{33}$ and Reimers. ${ }^{34}$ In this study, the explained portion was calculated by multiplying the differences in average characteristics between the COPD/GERD and COPD/no GERD groups, using three different regression weights as proposed by Blinder and Oaxaca, and Neumark: 1) coefficients of the characteristics from the regression model using data of individuals with COPD/GERD (GERD weights);29,30 2) coefficients of the characteristics from the regression model using data of individuals with COPD/no GERD (COPD weights); and 3) coefficients of the characteristics from the regression model using data from both COPD/ GERD and COPD/no GERD individuals (pooled weights). ${ }^{32}$ The pooled regression model did not include GERD status as one of the independent variables in the regression model. Therefore, the explained portion can vary depending on whether GERD weights, COPD weights, or pooled weights were used.

\section{Results}

In this study sample, $29.3 \%$ of the elderly Medicare beneficiaries with COPD had co-occurring GERD. The comparison of beneficiary characteristics among individuals with COPD/ GERD and COPD/no GERD (presented in Table 1) did not reveal any statistically significant differences in predisposing characteristics, enabling resources, personal health care practices, or external environment. However, differences in
Table I Description of study sample characteristics by GERD among elderly Medicare beneficiaries with COPD Medicare Current Beneficiary Survey, 2006-2009

\begin{tabular}{|c|c|c|c|c|c|}
\hline & \multicolumn{2}{|c|}{ GERD } & \multicolumn{2}{|c|}{ No GERD } & \multirow[t]{2}{*}{$P$-value } \\
\hline & $\mathbf{N}$ & $\mathbf{W t} \%$ & $\mathbf{N}$ & $\mathbf{W t} \%$ & \\
\hline Total & 746 & 29.3 & I,7।5 & 70.7 & \\
\hline \multicolumn{6}{|l|}{ Sex } \\
\hline Female & 380 & 51.7 & 880 & 52.0 & \\
\hline Male & 366 & 48.3 & 835 & 48.0 & \\
\hline \multicolumn{6}{|l|}{ Age } \\
\hline $65-69$ years & 124 & 17.6 & 249 & 17.3 & \\
\hline 70-74 years & 155 & 22.9 & 359 & 23.8 & \\
\hline$\geq 75$ years & 467 & 59.4 & $\mathrm{I}, 107$ & 59.0 & \\
\hline \multicolumn{6}{|l|}{ Race/ethnicity } \\
\hline White & 635 & 85.7 & $\mathrm{I}, 48 \mathrm{I}$ & 86.2 & \\
\hline African American & 39 & 5.4 & 89 & 5.6 & \\
\hline Latino & 35 & 4.1 & 66 & 3.4 & \\
\hline Other & 36 & 4.7 & 78 & 4.8 & \\
\hline \multicolumn{6}{|l|}{ Marital status } \\
\hline Married & 362 & 49.2 & 810 & 49.1 & \\
\hline Not married & 384 & 50.8 & 903 & 50.9 & \\
\hline \multicolumn{6}{|l|}{ Metropolitan status } \\
\hline Urban & 506 & 70.3 & I, I39 & 68.5 & \\
\hline Rural & 240 & 29.7 & 576 & 31.5 & \\
\hline \multicolumn{6}{|l|}{ Education } \\
\hline Less than high school & 256 & 32.9 & 581 & 32.5 & \\
\hline High school & 286 & 39.8 & 641 & 37.8 & \\
\hline Above high school & 201 & 27.3 & 486 & 29.7 & \\
\hline \multicolumn{6}{|l|}{ Poverty status } \\
\hline$<200 \% \mathrm{FPL}$ & 450 & 59.3 & 1,008 & 57.3 & \\
\hline $200 \%-400 \% \mathrm{FPL}$ & 224 & 31.2 & 507 & 30.2 & \\
\hline$\geq 400 \% \mathrm{FPL}$ & 72 & 9.5 & 200 & 12.4 & \\
\hline \multicolumn{6}{|l|}{ Medicaid status } \\
\hline Yes & 160 & 20.9 & 308 & 17.0 & \\
\hline No & 586 & 79.1 & I,407 & 83.0 & \\
\hline Perceived health & & & & & $* * *$ \\
\hline Excellent/very good & 137 & 18.5 & 432 & 25.3 & \\
\hline Good & 246 & 33.6 & 613 & 36.4 & \\
\hline Fair & 226 & 30.5 & 441 & 26.1 & \\
\hline Poor & 130 & 17.5 & 215 & 12.2 & \\
\hline Smoking status & & & & & $*$ \\
\hline Current smoker & 121 & 16.7 & 359 & 22.5 & \\
\hline Past smoker & 479 & 65.3 & 1,050 & 61.1 & \\
\hline Never smoker & $14 \mid$ & 18.0 & 297 & 16.4 & \\
\hline \multicolumn{6}{|l|}{ Body mass index } \\
\hline Underweight/normal & 268 & 35.7 & 700 & 40.4 & \\
\hline Overweight & 272 & 36.9 & 591 & 33.9 & \\
\hline Obese & 198 & 27.3 & 414 & 25.7 & \\
\hline Depression & & & & & $* * *$ \\
\hline Yes & 166 & 22.0 & 208 & 12.3 & \\
\hline No & 580 & 78.0 & I,507 & 87.7 & \\
\hline Anxiety & & & & & $* * *$ \\
\hline Yes & 124 & 16.2 & $|5|$ & 9.0 & \\
\hline No & 622 & 83.8 & I,564 & 91.0 & \\
\hline
\end{tabular}


Table I (Continued)

\begin{tabular}{lllllll}
\hline & \multicolumn{2}{l}{ GERD } & & \multicolumn{2}{c}{ No GERD } & P-value \\
& $\mathbf{N}$ & $\mathbf{W t} \%$ & & $\mathbf{N}$ & $\mathbf{W t} \%$ & \\
\hline Total & $\mathbf{7 4 6}$ & $\mathbf{2 9 . 3}$ & & $\mathbf{I , 7 1 5}$ & $\mathbf{7 0 . 7}$ & \\
\hline CCl categories & & & & & & *** \\
I & 90 & 12.4 & & 342 & 20.7 & \\
2 & 122 & 17.2 & & $37 \mid$ & 21.9 & \\
3 & 163 & 21.7 & & 315 & 18.2 & \\
4 & 106 & 14.7 & & 246 & 14.4 & \\
$\geq 5$ & 265 & 34.0 & & $44 \mid$ & 25.0 & \\
\hline
\end{tabular}

Notes: Based on 2,46I elderly Medicare beneficiaries with COPD who were observed between years 2006 and 2009. Asterisks represent significant association between the presence of GERD and beneficiary characteristics, based on chi-square tests. $* * * P<0.001 ; * 0.01 \leq P<0.05$

Abbreviations: $\mathrm{CCl}$, Charlson's Comorbidity Index; COPD, chronic obstructive pulmonary disease; FPL, federal poverty line; GERD, gastroesophageal reflux disease; Wt, weighted.

need variables were statistically significant between the two groups. Elderly Medicare beneficiaries with COPD/GERD had higher rates of poor perceived physical health $(17.5 \% \mathrm{vs}$ $12.2 \%[P<0.001])$, depression ( $22 \%$ vs $12.3 \%[P<0.001])$, anxiety $(16.2 \%$ vs $9.0 \%[P<0.001])$, and CCI $(\geq 5)$ score $(34.0 \%$ vs $25.0 \%[P<0.001])$ compared with those with COPD/no GERD.

Among the elderly Medicare beneficiaries with COPD, the average health care expenditure was $\$ 28,264$. Table 2 presents the comparison of average health care expenditures among individuals with COPD/GERD and COPD/ no GERD. For ease of interpretation, we also calculated the "ratio of means," obtained by dividing the average health care expenditures of the COPD/GERD group by the average health care expenditures of the COPD/no GERD group. Among all elderly Medicare beneficiaries, those with COPD/ GERD had 1.5 times higher $(\$ 36,793$ vs $\$ 24,722[P<0.001]$ ) expenditures than did beneficiaries with COPD/no GERD. Statistically significant differences in average health care expenditures among the COPD/GERD and COPD/no GERD groups were obtained for each of the beneficiary characteristics. The average health care expenditures for COPD/GERD group were significantly greater for all groups except the Whites, African Americans, Latinos, and those with income greater than $400 \%$ FPL. The ratio of means ranged from as high as $1.69(\mathrm{CCI}=1)$ to as low as 1.12 (poverty status $\geq 400 \% \mathrm{FPL}$ ).

Table 3 summarizes the results from separate OLS regression models on average log-transformed health care expenditures among the COPD/GERD and COPD/no GERD groups. The bottom panel of the table also presents the intercept, parameter estimate and significance of the
Table 2 Description of average annual health care expenditures by GERD among elderly Medicare beneficiaries with COPD Medicare Current Beneficiary Survey, 2006-2009

\begin{tabular}{|c|c|c|c|c|}
\hline & GERD & No GERD & $\begin{array}{l}\text { Ratio of } \\
\text { means }\end{array}$ & $P$-value \\
\hline All & $\$ 36,793$ & $\$ 24,722$ & 1.49 & $* * *$ \\
\hline \multicolumn{5}{|l|}{ Sex } \\
\hline Female & $\$ 35,446$ & $\$ 23,674$ & 1.50 & $* * *$ \\
\hline Male & $\$ 37,261$ & $\$ 25,877$ & 1.44 & $* * *$ \\
\hline \multicolumn{5}{|l|}{ Age } \\
\hline $65-69$ years & $\$ 35,622$ & $\$ 23,928$ & 1.49 & $* *$ \\
\hline $70-74$ years & $\$ 32,950$ & $\$ 22,834$ & 1.44 & $* *$ \\
\hline$\geq 75$ years & $\$ 37,880$ & $\$ 25,740$ & 1.47 & $* * *$ \\
\hline \multicolumn{5}{|l|}{ Race/ethnicity } \\
\hline White & $\$ 43,343$ & $\$ 31,964$ & 1.36 & \\
\hline African American & $\$ 52,436$ & $\$ 33,640$ & 1.56 & \\
\hline Latino & $\$ 36,816$ & $\$ 25,970$ & 1.42 & \\
\hline Other & $\$ 35,061$ & $\$ 23,864$ & 1.47 & $* * *$ \\
\hline \multicolumn{5}{|l|}{ Marital status } \\
\hline Married & $\$ 33,393$ & $\$ 23,591$ & 1.42 & $* * *$ \\
\hline Not married & $\$ 39,203$ & $\$ 25,852$ & 1.52 & $* * *$ \\
\hline \multicolumn{5}{|l|}{ Metropolitan status } \\
\hline Urban & $\$ 36,397$ & $\$ 25,539$ & 1.43 & $* * *$ \\
\hline Rural & $\$ 36,177$ & $\$ 23,000$ & 1.57 & $* * *$ \\
\hline \multicolumn{5}{|l|}{ Education } \\
\hline Less than high school & $\$ 35,494$ & $\$ 25,191$ & 1.41 & $* * *$ \\
\hline High school & $\$ 33,810$ & $\$ 24,045$ & $1.4 \mathrm{I}$ & $* * *$ \\
\hline Above high school & $\$ 40,068$ & $\$ 25,136$ & 1.59 & $* * *$ \\
\hline \multicolumn{5}{|l|}{ Poverty status } \\
\hline$<200 \% \mathrm{FPL}$ & $\$ 32,336$ & $\$ 22,623$ & 1.43 & $* * *$ \\
\hline $200 \%-400 \% \mathrm{FPL}$ & $\$ 39,133$ & $\$ 24,979$ & 1.57 & $* * *$ \\
\hline$\geq 400 \% \mathrm{FPL}$ & $\$ 32,311$ & $\$ 28,943$ & 1.12 & \\
\hline \multicolumn{5}{|l|}{ Medicaid status } \\
\hline Yes & $\$ 41,840$ & $\$ 28,831$ & 1.45 & $* * *$ \\
\hline No & $\$ 34,901$ & $\$ 23,915$ & 1.46 & $* * *$ \\
\hline \multicolumn{5}{|l|}{ Perceived health } \\
\hline Excellent/very good & $\$ 24,987$ & $\$ 16,040$ & 1.56 & $* * *$ \\
\hline Good & $\$ 37,621$ & $\$ 30,303$ & 1.24 & $* *$ \\
\hline Fair & $\$ 33,472$ & $\$ 22,189$ & 1.51 & $* * *$ \\
\hline Poor & $\$ 52,000$ & $\$ 38,713$ & 1.34 & $* *$ \\
\hline \multicolumn{5}{|l|}{ Smoking status } \\
\hline Current smoker & $\$ 30,634$ & $\$ 19,260$ & 1.59 & $* * *$ \\
\hline Past smoker & $\$ 35,277$ & $\$ 25,277$ & 1.40 & $*$ \\
\hline Never smoker & $\$ 38,069$ & $\$ 26,611$ & 1.43 & $* * *$ \\
\hline \multicolumn{5}{|l|}{ Body mass index } \\
\hline Underweight/normal & $\$ 38,908$ & $\$ 25,449$ & 1.53 & $* * *$ \\
\hline Overweight & $\$ 34,281$ & $\$ 23,113$ & 1.48 & $* * *$ \\
\hline Obese & $\$ 36,486$ & $\$ 25,652$ & 1.42 & $* * *$ \\
\hline \multicolumn{5}{|l|}{ Depression } \\
\hline Yes & $\$ 44,790$ & $\$ 35,850$ & 1.25 & $*$ \\
\hline No & $\$ 33,931$ & $\$ 23,163$ & 1.46 & $* * *$ \\
\hline \multicolumn{5}{|l|}{ Total } \\
\hline \multicolumn{5}{|l|}{ Anxiety } \\
\hline Yes & $\$ 38,223$ & $\$ 30,898$ & 1.24 & $*$ \\
\hline No & $\$ 35,964$ & $\$ 24,139$ & 1.49 & $* * *$ \\
\hline
\end{tabular}


Table 2 (Continued)

\begin{tabular}{lllll}
\hline & GERD & No GERD & $\begin{array}{l}\text { Ratio of } \\
\text { means }\end{array}$ & P-value \\
\hline CCl categories & & & & \\
I & $\$ 18,252$ & $\$ 10,813$ & 1.69 & $* * *$ \\
2 & $\$ 20,769$ & $\$ 15,534$ & 1.34 & $* *$ \\
3 & $\$ 28,243$ & $\$ 22,044$ & 1.28 & $* *$ \\
4 & $\$ 41,259$ & $\$ 27,749$ & 1.49 & $* * *$ \\
$\geq 5$ & $\$ 54,362$ & $\$ 44,726$ & 1.22 & $* *$ \\
\hline
\end{tabular}

Notes: Based on 2,46I elderly Medicare beneficiaries with COPD who were observed between years 2006 and 2009. Asterisks represent significant subgroup difference in total annual health care expenditures, by beneficiary characteristics among those with and without GERD, based on $t$-tests. ${ }^{*} * * P<0.001$; $* * 0.00 I \leq P<0.01$; $* 0.0 \mathrm{I} \leq \mathrm{P}<0.05$.

Abbreviations: $\mathrm{CCl}$, Charlson's Comorbidity Index; COPD, chronic obstructive pulmonary disease; FPL, federal poverty line; GERD, gastroesophageal reflux disease; Wt, weighted.

COPD/GERD indicator variable, which was obtained from a pooled OLS regression on average log-transformed health care expenditures. As seen from the bottom panel, the presence of GERD was associated with greater expenditures. Elderly Medicare beneficiaries with COPD/GERD had 36.3\% $\exp ^{(\beta)}-1(P<0.001)$ higher expenditures than did those with COPD/no GERD.

\section{Blinder-Oaxaca linear decomposition analysis}

The results from the postregression Blinder-Oaxaca linear decomposition analysis are summarized in Table 4. The average log-transformed health care expenditure for the COPD/GERD group was 10.165 units; the corresponding figure for COPD/no GERD was 9.651 units. This represented a difference of 0.514 units in average log-transformed health care expenditures. Using GERD weights, of this difference, it was found that differences in predisposing characteristics, enabling resources, need variables, personal health care practices, and external environment only explained 0.16 units. This represented $30.95 \%$ of the differences in average log-transformed health care expenditures. Using pooled weights, a 0.22 -unit difference was explained by differences in beneficiary characteristics. Thus, the explained portion represented $(0.22 / 0.51) 42.39 \%$ of the differences in average log-transformed health care expenditures between the two groups. When COPD weights were used, 0.29 units were due to differences in beneficiary characteristics between the two groups. This represented $43.56 \%$ of the differences in average log-transformed health care expenditures.

Further examination of the decomposition results revealed that differences in CCI score explained $22.2 \%$ of the differences in average log transformed health care expenditures between the two groups using pooled weights. This can be interpreted as follows: keeping all the factors same, if COPD/GERD group had a similar distribution of CCI score as compared to those with COPD/no GERD, the average log-transformed health care expenditures would decrease by 0.114 units. The presence of depression and/or anxiety contributed 0.05 units (9.7\%) to the explained portion. If COPD/ GERD group had similar rates of depression and/or anxiety as the COPD/no GERD group, the difference in average logtransformed expenditures would be reduced by 0.05 units. Predisposing characteristics, enabling resources, personal health practices and external environment contributed to a very small portion $(2.5 \%)$ of explained portion of the differences in average log-transformed health care expenditures.

Similar findings were observed when COPD weights and GERD weights were used. When GERD weights were used, the CCI score contributed to $17.5 \%$ of the explained portion of the difference in average log-transformed health care expenditures; whereas, when COPD weights were used, the CCI score contributed to $23.6 \%$ of the explained portion of difference in log-transformed average expenditures between the two groups.

\section{Discussion}

This study examined the excess health care expenditures associated with GERD among elderly Medicare beneficiaries with COPD, using a nationally representative survey linked to Medicare fee-for-service claims. In this study, the overall prevalence of GERD was $29.3 \%$. Although no study has specifically examined the prevalence of GERD in elderly individuals with COPD, our estimates are somewhat consistent with those reported in a review (ranging from $30 \%$ to $60 \%$ ) of the literature on extrapulmonary comorbidities in COPD. ${ }^{10}$

Even after controlling for predisposing characteristics, enabling resources, need variables, personal health care practices, and external environment, the presence of GERD was associated with $36 \%$ higher $(P<0.001)$ health care expenditures. The excess expenditures associated with GERD status can be due to several factors. Previous studies have suggested that the presence of GERD among individuals with COPD aggravated respiratory infections ${ }^{35}$ and increased the risk of COPD-related exacerbations, ${ }^{12,15,16,36}$ which may lead to higher health care expenditures. Conversely, common COPD manifestations, such as lung hyperinflation, can also complicate GERD symptoms, ${ }^{37,38}$ leading to higher expenditures The presence of GERD may also increase other complications, 
Table 3 Factors associated with total health care expenditures: results from ordinary least squares regression on logged expenditures Medicare Current Beneficiary Survey, 2006-2009

\begin{tabular}{|c|c|c|c|c|c|c|c|c|c|}
\hline & \multicolumn{3}{|c|}{ No GERD } & \multicolumn{3}{|l|}{ GERD } & \multicolumn{3}{|c|}{ Pooled $^{\S}$} \\
\hline & Beta & SE & $P$ & Beta & SE & $\mathbf{P}$ & Beta & SE & $P$ \\
\hline Intercept & 9.960 & 0.213 & $* * *$ & 9.569 & 0.163 & $* * *$ & 9.663 & 0.152 & $* * *$ \\
\hline \multicolumn{10}{|l|}{ Sex } \\
\hline Female & 0.026 & 0.065 & & -0.035 & 0.058 & & -0.027 & 0.045 & \\
\hline \multicolumn{10}{|l|}{ Male } \\
\hline \multicolumn{10}{|l|}{ Age } \\
\hline $65-69$ years & -0.030 & 0.102 & & -0.029 & 0.072 & & -0.035 & 0.066 & \\
\hline $70-74$ years & -0.110 & 0.084 & & -0.031 & 0.061 & & -0.049 & 0.055 & \\
\hline \multicolumn{10}{|l|}{$\geq 75$ years } \\
\hline \multicolumn{10}{|l|}{ Race } \\
\hline African American & -0.038 & 0.143 & & 0.066 & 0.119 & & 0.020 & 0.088 & \\
\hline Latino & 0.077 & 0.172 & & 0.102 & 0.118 & & 0.087 & 0.096 & \\
\hline Other & -0.193 & 0.119 & & -0.036 & 0.102 & & -0.109 & 0.083 & \\
\hline \multicolumn{10}{|l|}{ White } \\
\hline \multicolumn{10}{|l|}{ Marital status } \\
\hline Married & -0.121 & 0.073 & & -0.125 & 0.045 & $* *$ & -0.115 & 0.036 & $* *$ \\
\hline \multicolumn{10}{|l|}{ Not married } \\
\hline \multicolumn{10}{|l|}{ Metropolitan status } \\
\hline Urban & -0.039 & 0.059 & & 0.039 & 0.059 & & 0.027 & 0.048 & \\
\hline \multicolumn{10}{|l|}{ Rural } \\
\hline \multicolumn{10}{|l|}{ Education } \\
\hline Less than high school & -0.065 & 0.094 & & -0.101 & 0.058 & & -0.097 & 0.054 & \\
\hline High school & -0.142 & 0.097 & & -0.095 & 0.056 & & -0.112 & 0.054 & $*$ \\
\hline \multicolumn{10}{|l|}{ Above high school } \\
\hline \multicolumn{10}{|l|}{ Poverty status } \\
\hline$<200 \% \mathrm{FPL}$ & 0.001 & 0.088 & & -0.208 & 0.093 & $*$ & -0.148 & 0.074 & $*$ \\
\hline $200 \%-400 \% \mathrm{FPL}$ & -0.070 & 0.093 & & -0.149 & 0.078 & & -0.123 & 0.067 & \\
\hline \multicolumn{10}{|l|}{$\geq 400 \% \mathrm{FPL}$} \\
\hline Medicaid coverage & & & & & & & & & \\
\hline Medicaid & -0.041 & 0.092 & & 0.075 & 0.060 & & 0.061 & 0.045 & \\
\hline No Medicaid & & & & & & & & & \\
\hline Health status & & & & & & & & & \\
\hline Excellent/very good & -0.539 & 0.110 & $* * *$ & -0.550 & 0.074 & $* * *$ & -0.562 & 0.064 & $* * *$ \\
\hline Good & -0.256 & 0.092 & $* *$ & -0.366 & 0.061 & $* * *$ & -0.347 & 0.058 & $* * *$ \\
\hline Fair & -0.187 & 0.074 & $*$ & -0.141 & 0.064 & $*$ & -0.149 & 0.050 & $* *$ \\
\hline Poor & & & & & & & & & \\
\hline Smoking status & & & & & & & & & \\
\hline Current smoker & -0.119 & 0.106 & & -0.215 & 0.074 & $* *$ & -0.226 & 0.069 & $* *$ \\
\hline Past smoker & 0.067 & 0.085 & & 0.057 & 0.060 & & 0.053 & 0.050 & \\
\hline Never smoked & & & & & & & & & \\
\hline Body mass index & & & & & & & & & \\
\hline Underweight/normal & 0.020 & 0.076 & & -0.045 & 0.071 & & -0.027 & 0.058 & \\
\hline Overweight & -0.056 & 0.074 & & -0.088 & 0.050 & & -0.068 & 0.042 & \\
\hline Obese & & & & & & & & & \\
\hline Depression & & & & & & & & & \\
\hline Yes & 0.310 & 0.069 & $* * *$ & 0.276 & 0.061 & $* * *$ & 0.324 & 0.052 & $* * *$ \\
\hline No & & & & & & & & & \\
\hline Anxiety & & & & & & & & & \\
\hline Yes & 0.010 & 0.074 & & 0.325 & 0.077 & $* * *$ & 0.251 & 0.051 & $* * *$ \\
\hline No & & & & & & & & & \\
\hline $\mathrm{CCl}$ & 0.147 & 0.012 & $* * *$ & 0.198 & 0.011 & $* * *$ & 0.186 & 0.008 & $* * *$ \\
\hline Pooled regression co & for pre & of GE & & & & & & & \\
\hline Intercept & 9.594 & 0.148 & $* * *$ & & & & & & \\
\hline
\end{tabular}


Table 3 (Continued)

\begin{tabular}{|c|c|c|c|c|c|c|c|c|c|}
\hline & \multicolumn{3}{|c|}{ No GERD } & \multicolumn{3}{|c|}{ GERD } & \multicolumn{3}{|c|}{ Pooled ${ }^{\S}$} \\
\hline & Beta & SE & $P$ & Beta & SE & $P$ & Beta & SE & $P$ \\
\hline \multicolumn{10}{|l|}{ GERD } \\
\hline Yes & 0.310 & 0.037 & $* * *$ & & & & & & \\
\hline No & & & & & & & & & \\
\hline
\end{tabular}

Notes: Based on 2,46I elderly Medicare beneficiaries with COPD who were observed between years 2006 and 2009. Asterisks represent significant group differences in logtransformed total health care expenditures, based on ordinary least squares regression models. Blank rows represent the reference groups. $\$$ Pooled regression coefficients are obtained from the regression model without GERD status as one of the independent variables. $* * * P<0.001 ; * * 0.001 \leq P<0.01 ; * 0.01 \leq P<0.05$.

Abbreviations: $\mathrm{CCl}$, Charlson's Comorbidity Index; COPD, chronic obstructive pulmonary disease; FPL, federal poverty line; GERD, gastroesophageal reflux disease; $\mathrm{SE}$, standard error; Wt, weighted.

such as chest pain, chronic cough, and sinusitis, ${ }^{39}$ that may increase overall health care expenditures.

The current study also used the unique Blinder-Oaxaca linear decomposition technique, to examine the extent to which the differences in predisposing characteristics, enabling resources, need variables, personal health care practices, and external environment explained the difference in average health care expenditures between the two groups (COPD/GERD and COPD/no GERD). Need variables (CCI, perceived health status, anxiety, and depression) primarily explained the difference in average log-transformed health care expenditures between the two groups. The findings from this study highlight the role of comanagement of chronic conditions among elderly individuals with COPD. Multimorbidity, defined by the presence of two or more coexisting chronic conditions, is a major challenge among elderly individuals. ${ }^{40,41}$ In this context, our study strengthens the need for developing clinical practice guidelines for comanagement of multiple chronic conditions. Additionally, the findings from this study highlight the importance of emerging health care delivery models, such as "medical homes," in reducing health care expenditures. These models emphasize care-coordination for management of the elderly Medicare beneficiaries with multiple chronic conditions, to improve outcomes. In addition, the recently introduced chronic care management and fiscal incentives for providing care to elderly with multiple chronic conditions may lead to reduced health care expenditures. ${ }^{42}$

A noteworthy finding of our study is that more than 50\% of the difference in average log-transformed health care expenditures between the two groups remained unexplained. It is plausible that some portion of this difference could be due to unmeasured factors related to COPD and GERD, such as medication adherence, severity of COPD, severity of GERD, symptomatology, health beliefs, and propensity to seek care. Therefore, future research needs to evaluate the contributions of such factors in assessing excess health care expenditures among elderly individuals with COPD and GERD.

Our study has many advantages and some limitations. The advantages include the use of a nationally representative survey of elderly Medicare beneficiaries linked to their fee-for-service claims data, the clinical diagnosis of COPD and GERD using validated ICD-9-CM codes, ${ }^{24,43}$ the large sample size, and the comprehensive set of independent factors that can influence health care expenditures. It could be suggested that the identification of individuals with COPD using

Table 4 Factors explaining excess health care expenditures with presence of GERD among elderly Medicare beneficiaries having COPD (Blinder-Oaxaca linear decomposition analysis) Medicare Current Beneficiary Survey, 2006-2009

\begin{tabular}{llll}
\hline & GERD weights & COPD weights & Pooled weights \\
\hline Total difference explained (log units) & 0.159 & 0.290 & 0.216 \\
Predisposing characteristics (age, race, sex) & $0.31 \%$ & $0.18 \%$ & $0.22 \%$ \\
Enabling resources (education, marital status, & $-1.06 \%$ & $-1.00 \%$ & $-0.54 \%$ \\
Medicaid coverage, metropolitan status, poverty status) & & & $0.14 \%$ \\
External environment (metropolitan status) & $-0.14 \%$ & $31.69 \%$ & $0.00 \%$ \\
Physical health need variables (CCl, health status) & $24.47 \%$ & $9.76 \%$ & $30.24 \%$ \\
Mental health need variables (anxiety, depression) & $5.99 \%$ & $2.79 \%$ & $9.64 \%$ \\
Personal health care practices (BMI, smoking status) & $1.38 \%$ & $43.56 \%$ & $2.83 \%$ \\
Total difference explained & $30.95 \%$ & $42.39 \%$ \\
\hline
\end{tabular}

Notes: Based on 2,46I elderly Medicare beneficiaries with COPD, who were observed between years 2006 and 2009. For the ease of representation, the percent differences are explained for the group of characteristics. (These groups are derived from the Andersen's health care behavior model). $\mathrm{Ln}_{\text {exp }}(\mathrm{COPD} / \mathrm{GERD})=$ predicted average logtransformed total health care expenditures for the COPD/GERD group; $\ln _{\text {exp }}(C O P D / n o G E R D)=$ predicted average log-transformed total health care expenditures for COPD/no GERD group; $\ln _{\text {exp }}\left(\right.$ COPD/GERD) $=10.165 ; \ln _{\text {exp }}\left(C O P D / n o\right.$ GERD) $=9.651 ; \ln _{\text {exp }}(C O P D / G E R D)-\ln _{\text {exp }}(C O P D / n o G E R D)=0.514$.

Abbreviations: BMI, body mass index; CCI, Charlson's Comorbidity Index; COPD, chronic obstructive pulmonary disease; GERD, gastroesophageal reflux disease. 
ICD-9-CM diagnoses codes may not be the most accurate method; however, the ICD-9-CM codes used in this study have been previously validated and also utilized in several prior studies. ${ }^{24}$ This study also used a unique Blinder-Oaxaca linear decomposition technique to identify the factors that contribute to excess health care expenditures. ${ }^{29,30}$ A limitation of this study was the lack of information on the severity and duration of COPD and GERD. However, the current study adjusted for perceived health status, which would serve as a proxy for overall disease severity. Also, although the decomposition technique is important in quantifying the contribution of each factor in explaining the difference in average health care expenditures, it cannot point to the underlying mechanisms behind the differences in health care expenditures. In addition, the findings from this study can only be generalizable to community-dwelling, fee-for-service Medicare enrollees.

\section{Conclusion}

In conclusion, this is the first study to assess excess health care expenditures associated with GERD among elderly individuals with COPD, using a nationally representative survey linked to Medicare fee-for-service claims. Individuals with co-occurring COPD/GERD had significantly higher total health care expenditures than did those with COPD/no GERD, even after controlling for a comprehensive set of independent variables. Blinder-Oaxaca linear decomposition revealed that the CCI score, perceived health status, anxiety, and depression explained the major portion of the differences in average total health care expenditures between the two groups. This finding suggests that comprehensive and coordinated health care management of individuals with co-occurring COPD and GERD may be necessary, to reduce excess health care expenditures associated with GERD.

\section{Disclosure}

The views expressed in this academic research paper are those of the authors and do not reflect the official policy or position of West Virginia University or any other affiliated organizations.

The authors report no conflicts of interest in this work.

\section{References}

1. Global Initiative for Chronic Obstructive Pulmonary Disease (GOLD). Global Strategy for Diagnosis, Management, and Prevention of Chronic Obstructive Pulmonary Disease. Revised 2011. Barcelona: Global Initiative for Chronic Obstructive Pulmonary Disease; 2011. Available from: http://www.goldcopd.org/uploads/users/files/GOLD_Report_2011_ Feb21.pdf. Accessed February 26, 2014.
2. nhlbi.nih.gov [homepage on the Internet]. 2012 NHLBI mortality and morbidity chartbook. National Heart, Lung, and Blood Institute; 2012 [updated May 2013]. Available from: http://www.nhlbi.nih.gov/ resources/docs/cht-book.htm. Accessed February 26, 2014.

3. Han MK. Update in chronic obstructive pulmonary disease in 2010 Am J Respir Crit Care Med. 2011;183(10):1311-1315.

4. Guarascio AJ, Ray SM, Finch CK, Self TH. The clinical and economic burden of chronic obstructive pulmonary disease in the USA. Clinicoecon Outcomes Res. 2013;5:235-245.

5. Dalal AA, Shah M, D'Souza AO, Rane P. Costs of COPD exacerbations in the emergency department and inpatient setting. Respir Med. 2011;105(3):454-460.

6. Oostenbrink JB, Rutten-van Mölken MP. Resource use and risk factors in high-cost exacerbations of COPD. Respir Med. 2004;98(9): 883-891.

7. Sullivan SD, Ramsey SD, Lee TA. The economic burden of COPD. Chest. 2000;117(2):5S-9S.

8. Stuart B, Doshi JA, Briesacher B, Wrobel MV, Baysac F. Impact of prescription coverage on hospital and physician costs: a case study of Medicare beneficiaries with chronic obstructive pulmonary disease. Clin Ther. 2004;26(10):1688-1699.

9. Donaldson GC, Müllerova H, Locantore N, et al. Factors associated with change in exacerbation frequency in COPD. Respir Res. 2013; 14:79.

10. Patel AR, Hurst JR. Extrapulmonary comorbidities in chronic obstructive pulmonary disease: state of the art. Expert Rev Respir Med. 2011;5(5):647-662.

11. Burge PS. Prevention of exacerbations: how are we doing and can we do better? Proc Am Thorac Soc. 2006;3(3):257-261.

12. Ozyilmaz E, Kokturk N, Teksut G, Tatlicioglu T. Unsuspected risk factors of frequent exacerbations requiring hospital admission in chronic obstructive pulmonary disease. Int J Clin Pract. 2013;67(7): 691-697.

13. Rascon-Aguilar IE, Pamer M, Wludyka P, et al. Role of gastroesophageal reflux symptoms in exacerbations of COPD. Chest. 2006;130(4): 1096-1101.

14. Terada K, Muro S, Sato S, et al. Impact of gastro-oesophageal reflux disease symptoms on COPD exacerbation. Thorax. 2008;63(11): 951-955.

15. Sakae TM, Pizzichini MM, Teixeira PJ, da Silva RM, Trevisol DJ, Pizzichini E. Exacerbations of COPD and symptoms of gastroesophageal reflux: a systematic review and meta-analysis. J Bras Pneumol. 2013;39(3):259-271.

16. Kim J, Lee JH, Kim Y, et al. Association between chronic obstructive pulmonary disease and gastroesophageal reflux disease: a national cross-sectional cohort study. BMC Pulm Med. 2013;13(1):51.

17. cdc.gov [homepage on the Internet]. Chronic obstructive pulmonary disease among adults - United States, 2011. Centers for Disease Control and Prevention; 2012 [updated November 23, 2012; cited July 6, 2013]. Available from: http://www.cdc.gov/mmwr/preview/mmwrhtml/ mm6146a2.htm. Accessed February 26, 2014.

18. Centers for Disease Control and Prevention (CDC). Chronic obstructive pulmonary disease among adults - United States, 2011. MMWR Morb Mortal Wkly Rep. 2012;61(46):938-943.

19. Menzin J, Boulanger L, Marton J, et al. The economic burden of chronic obstructive pulmonary disease (COPD) in a US Medicare population. Respir Med. 2008;102(9):1248-1256.

20. cms.gov [homepage on the Internet]. Medicare Current Beneficiary Survey. Centers for Medicare and Medicaid Services; 2013 [updated July 18, 2013; cited August 6, 2013]. Available from: http://www.cms. gov/Research-Statistics-Data-and-Systems/Research/MCBS/index. html?redirect=/MCBS. Accessed February 26, 2014.

21. Dalal AA, Shah M, va AO, Chaudhari S, Crater G. Clinical and economic outcomes for patients initiating fluticasone propionate/salmeterol combination therapy $(250 / 50 \mathrm{mcg})$ versus anticholinergics in a comorbid COPD/depression population. Int J Chron Obstruct Pulmon Dis. 2012;7: 11-19. 
22. Halpern R, Baker CL, Su J, et al. Outcomes associated with initiation of tiotropium or fluticasone/salmeterol in patients with chronic obstructive pulmonary disease. Patient Prefer Adherence. 2011;5:375-388.

23. Make B, Dutro MP, Paulose-Ram R, Marton JP, Mapel DW. Undertreatment of COPD: a retrospective analysis of US managed care and Medicare patients. Int J Chron Obstruct Pulmon Dis. 2012;7:1-9.

24. Gershon AS, Wang C, Guan J, Vasilevska-Ristovska J, Cicutto L, To T. Identifying individuals with physician diagnosed COPD in health administrative databases. COPD. 2009;6(5):388-394.

25. bls.gov [homepage on the Internet]. Consumer price index. Bureau of Labor Statistics, Department of Labor; 2001 [updated October 16, 2001; cited August 10, 2013]. Available from: http://www.bls.gov/cpi/ cpiovrvw.htm. Accessed February 26, 2014.

26. Gerson LB, McLaughlin T, Balu S, Jackson J, Lunacsek O. Variation of health-care resource utilization according to GERD-associated complications. Dis Esophagus. 2012;25(8):694-701.

27. Andersen RM. Revisiting the behavioral model and access to medical care: does it matter? J Health Soc Behav. 1995;36(1):1-10.

28. Halvorsen RP, Palmquist R. The interpretation of dummy variables in semilogarithmic equations. Am Econ Rev. 1980;70(3):474-475.

29. Blinder AS. Wage discrimination: Reduced form and structural estimates. J Hum Resour. 1973;8(4):436-455.

30. Oaxaca R. Male-female wage differentials in urban labor markets. Int Econ Rev. 1973;14(3):693-709.

31. Cotton J. On the decomposition of wage differentials. Rev Econ Stat. 1988;70(2):236-243.

32. Newumark D. Employers' discriminatory behavior and the estimation of wage discrimination. J Hum Resour. 1988;23(3):279-295.

33. Oaxaca RL, Ransom MR. Identification in detailed wage decompositions. Rev Econ Stat. 1999;81(1):154-157.
34. Reimers CW. Labor market discrimination against hispanic and black men. Rev Econ Stat. 1983;65(4):570-579.

35. Morehead RS. Gastro-oesophageal reflux disease and non-asthma lung disease. Eur Respir Rev. 2009;18(114):233-243.

36. Briggs DD, Doherty DE. Long-term pharmacologic management of patients with chronic obstructive pulmonary disease. Clin Cornerstone. 2004;Supp1 2:S17-S28.

37. Turbyville JC. Applying principles of physics to the airway to help explain the relationship between asthma and gastroesophageal reflux. Med Hypotheses. 2010;74(6):1075-1080.

38. O’Donnell DE. Hyperinflation, dyspnea, and exercise intolerance in chronic obstructive pulmonary disease. Proc Am Thorac Soc. 2006;3(2):180-184.

39. El-Serag H, Hill C, Jones R. Systematic review: the epidemiology of gastro-oesophageal reflux disease in primary care, using the UK General Practice Research Database. Aliment Pharmacol Ther. 2009;29(5): 470-480.

40. Ajmera M, Wilkins TL, Findley PA, Sambamoorthi U. Multimorbidity, mental illness, and quality of care: Preventable hospitalizations among Medicare beneficiaries. Int J Family Med. 2012;2012:823294.

41. Marengoni A, Angleman S, Melis R, et al. Aging with multimorbidity: a systematic review of the literature. Ageing Res Rev. 2011;10(4): 430-439.

42. Centers for Medicare and Medicaid Services. CMS finalizes physician payment rates for 2014 [press release]. Baltimore, MD: Centers for Medicare and Medicaid Services; 2013 [November 27]. Available from: http://www. cms.gov/Newsroom/MediaReleaseDatabase/Press-Releases/2013-PressReleases-Items/2013-11-27-2.html. Accessed December 05, 2013.

43. Cooke CR, Joo MJ, Anderson SM, et al. The validity of using ICD-9 codes and pharmacy records to identify patients with chronic obstructive pulmonary disease. BMC Health Serv Res. 2011;11:37.
International Journal of COPD

\section{Publish your work in this journal}

The International Journal of COPD is an international, peer-reviewed journal of therapeutics and pharmacology focusing on concise rapid reporting of clinical studies and reviews in COPD. Special focus is given to the pathophysiological processes underlying the disease, intervention programs, patient focused education, and self management protocols.

\section{Dovepress}

This journal is indexed on PubMed Central, MedLine and CAS. The manuscript management system is completely online and includes a very quick and fair peer-review system, which is all easy to use. Visit http://www.dovepress.com/testimonials.php to read real quotes from published authors. 